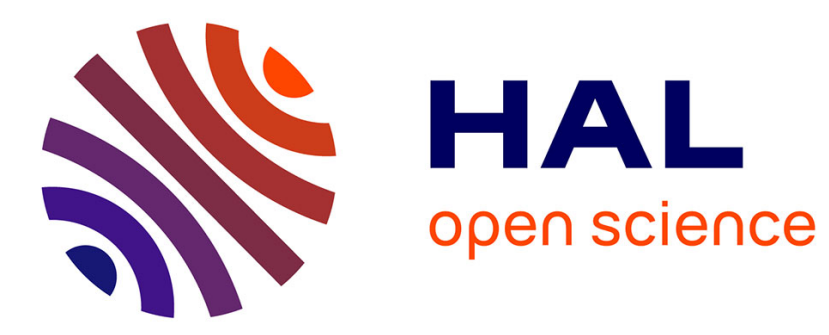

\title{
Parameter Optimization of the Steam Thermolysis: A Process to Recover Carbon Fibers from Polymer-Matrix Composites
}

Sheng Yin Ye, Arezki Bounaceur, Yannick Soudais, Radu Barna

\section{- To cite this version:}

Sheng Yin Ye, Arezki Bounaceur, Yannick Soudais, Radu Barna. Parameter Optimization of the Steam Thermolysis: A Process to Recover Carbon Fibers from Polymer-Matrix Composites. Waste and Biomass Valorization, 2013, 4 (1), pp.73-86. 10.1007/s12649-013-9220-4 . hal-01688103

\section{HAL Id: hal-01688103 https://hal.science/hal-01688103}

Submitted on 13 Dec 2018

HAL is a multi-disciplinary open access archive for the deposit and dissemination of scientific research documents, whether they are published or not. The documents may come from teaching and research institutions in France or abroad, or from public or private research centers.
L'archive ouverte pluridisciplinaire HAL, est destinée au dépôt et à la diffusion de documents scientifiques de niveau recherche, publiés ou non, émanant des établissements d'enseignement et de recherche français ou étrangers, des laboratoires publics ou privés. 


\title{
Parameter Optimization of the Steam Thermolysis: A Process to Recover Carbon Fibers from Polymer-Matrix Composites
}

\author{
Sheng Yin Ye $\cdot$ Arezki Bounaceur • \\ Yannick Soudais • Radu Barna
}

\begin{abstract}
Life cycle assessment has confirmed the effectiveness of carbon fiber reinforced polymer-matrix composite (CFRP) materials' application in $\mathrm{CO}_{2}$ reduction as well as in weight reduction (JCMA in 2008). Thanks to these strong and ultimate lightweight structure materials, burdens imposed by vehicles on environment nowadays could be significantly relieved. However, speedy manufacturing and recycle technology have to be established to apply to massproduction of automobiles using CFRP components. It is estimated that 3,000 $\mathrm{t}$ of CFRP scrap being generated annually in Europe and the USA. Some 6,000-8,000 commercial planes are expected to reach end-of-life dismantlement by 2030 (McConnell in Reinf Plast 54(2):33-37, 2010). Historically, CFRP waste has been disposed of in landfills. Since 2004, most European countries have banned the landfill disposal of CFRP waste. Future EU regulations will be imposed on the recycling of end-of-life aircraft along the same lines as those for scrapped vehicles. Besides, high cost of the carbon fibers is likely to be one of the strongest drivers for recycling of CFRP waste if an economic and environmentally friendly technology can be developed to provide a
\end{abstract}

S. Y. Ye $(\bowtie) \cdot$ A. Bounaceur $\cdot$ Y. Soudais $\cdot$ R. Barna École des Mines d'Albi, CNRS, Centre RAPSODEE, Campus Jarlard, 81013 Albi, France

e-mail: shengyin.ye@enstimac.fr

A. Bounaceur

e-mail: arezki.bounaceur@enstimac.fr

Y. Soudais

e-mail: yannick.soudais@enstimac.fr

R. Barna

e-mail: radu.barna@enstimac.fr

S. Y. Ye · A. Bounaceur

ADEME, 20, avenue du Grésillé, 49004 Angers, France potential sustainable resource of reusable fibers. Numerous recycling approaches have been proposed and investigated: microwave treatment (Lester et al. in Mater Res Bull 39(10):1549-1556, 2004), vacuum pyrolysis (Cunliffe et al. in J Anal Appl Pyrol 70(2):315-338, 2003), chemical solvolysis (Piñero-Hernanz et al. in J Supercrit Fluids 46(1):83-92, 2008; Goto in J Supercrit Fluids 47(3):500507, 2009), as well as hydro-thermolysis (Piñero-Hernanz et al. in Compos A 39(3):454-461, 2008). Steam thermolysis, a combination of vacuum pyrolysis and mild gasification, has been studied in our laboratory. The process takes place under medium temperatures (until $600{ }^{\circ} \mathrm{C}$ ) and atmospheric pressure. By using superheated steam as a soft oxidant, the polymer matrix can be converted into lower molecular weight hydrocarbons, $\mathrm{CO}$ and $\mathrm{CO}_{2}$ without seriously reducing the mechanical properties of the carbon fiber reinforcement. The steam-thermolysis has been studied and confirmed efficient in treating epoxy based CFRP materials at bench scale. In order to optimize the process, an experimental design has been carried out by using Taguchi method at semi-industrial scale. Initially, an orthogonal array testing was applied to determine the potential influence of the operational parameters on the decomposition rate of the polymer matrix as wall as on the mechanical property of the reclaimed carbon fibers. Three operational parameters at two levels each (target temperature, isothermal dwell time and steam flow-rate) were identified and tested. During the test, some $100 \mathrm{~g}$ epoxy based CFRP scrap samples were loaded into a thermal reactor preheated till desired temperature. The steam is flushed with a flow of nitrogen throughout the test to avoid oxidative side reactions. Additional tests were also conducted to complete and validate the results.

Keywords CFRP - Epoxy resin - Steam-thermolysis · Experimental design - Recycling 


\section{Introduction}

Replacing metal-based components with lightweight automotive composite components in a major way for fuel efficiency and low carbon emission and regulation also plays an important role in the raising demand for these valuable materials [1]. Life cycle assessment has before long confirmed the effectiveness of carbon fiber reinforced polymer-matrix composite (CFRP) materials' application in $\mathrm{CO}_{2}$ reduction as well as in weight reduction [2]. Carbon fiber reinforced polymer-matrix composite materials are being widely adopted in alternative vehicles such as electric/hybrid and fuel cell vehicles. However, the high costs of carbon fiber and existing production techniques result in higher manufacturing cycle times, which lead to low-volume production. There are also concerns over providing a waste disposal/recycling system for CFRP parts.

The EU legislation adopted in September 2000 [3] aims to put only $5 \%$, by an average weight per vehicle and year, of automotive shredder residues (ASR) into landfills not later than 2015. Although such target will be re-examined by the commission, taking into account of the development of the material compositions of vehicles, further regulations will probably be imposed on the recycling of end-of-life aircraft along the same lines as those for scrapped vehicles. Estimation shows that 3,000 $\mathrm{t}$ of carbon fiber reinforced composite (CFRP) scrap being generated annually in Europe and the USA. In addition, some 6,000-8,000 commercial planes are expected to reach end-of-life dismantlement by 2030 [4].

The versatile usage and the relatively high cost of the carbon fiber are likely to be the two strongest drivers for recycling of CFRP waste if an economic and environmentally friendly technology can be developed to provide a potential sustainable resource of reusable fibers. However, the uncertainty about how they can be cost-effectively processed is the major barrier of recycling. Numerous recycling approaches have been proposed and investigate. Lester et al. [5] has confirmed the possibility to separate polymer from carbon fibers in a multimode microwave cavity, which could offer a route to recovery of long fibers. Vacuum pyrolysis (in nitrogen), studied by Cunliffe et al. [6] showed that the pyrolysis temperature has a remarkable influence on the material balance as well as on the composition of the emitted gaseous phase. The decomposition of most plastic matrices is finished in a single step. However, the epoxy resin based composite continues to lose mass after the primary decomposition phase, which are suggested as the carbonization of the residues. Chemical solvolysis (at temperatures from 200 to $450{ }^{\circ} \mathrm{C}$ under subcritical and supercritical conditions) [7, 8], as well as hydro-thermolysis [9] (temperatures ranging from 523 to $673 \mathrm{~K}$, pressures from 4 to $28 \mathrm{MPa}$ and reaction times up to $30 \mathrm{~min}$ ) have also been tested.
Our laboratory has developed and tested a steam-thermal process to successfully extract quasi-unsized carbon fibers from polymer-matrix composite materials. Steam thermolysis is similar to a hydro-thermolysis, which combines a vacuum pyrolysis and a mild gasification together at medium temperatures (until $600{ }^{\circ} \mathrm{C}$ ) and atmospheric pressure. By using superheated steam as a soft oxidant, the polymer matrix can be completely decomposed into low molecular weight hydrocarbons, combustible gas such as $\mathrm{CO}, \mathrm{CH}_{4}, \mathrm{H}_{2}$, and $\mathrm{CO}_{2}$ without reducing too much the mechanical properties of the remaining carbon fiber reinforcement. The experimental results indicated the treatment as a technically and economically promising method. Nevertheless, it was found out that pyrolysis and certain conditions of steam-thermolysis resulted carbon fibers covered with residual pitch coke or char-like substance. Recovered carbon fiber layers whereby remain firmly sticked together and are hardly compatible for further transformation. As it is judged of ultimate importance to be able to retrieve clean (residue free) carbon fibers for further reuse, understanding and optimization of the steam-thermal process become a necessity.

Hence a Taguchi method based experimental design at semi-industrial scale was carried out, under varying operational parameters: target temperature, isothermal heating duration and steam flow-rate. The influences of each parameter on, firstly, the final decomposition rate of the polymer matrix, secondly, the tensile strength of the recovered carbon fibers were investigated by using analysis of variance and standard least squares linear regression analysis. Conventional pyrolytic treatments were also conducted in order to complete the experimental design as well as to compare the resulting carbon fibers with those obtained from steam thermolysis. The interpretation of the results can further guide us to predict the optimum of the operational parameter conditions. Notwithstanding the fact that such optimum is hard to conclude, we can confirm the validity of the used experimental design for retaining high mechanical performance of recovered carbon fibers while eliminating completely the carbonaceous structure issued from matrix degradation.

\section{Materials}

\section{CFRP Samples}

Two commercial grade epoxy based polymer-matrix composites made by ICA (Institute Clément Ader) at École des Mines d'Albi-Carmaux were chosen as reference sample materials. Composite sheets of $15 \mathrm{~cm} \times 15 \mathrm{~cm}$ (thickness: $4 \mathrm{~mm}$ ) were produced via resin transfer molding technique. Sample $A$ uses a mono component epoxy 
system cured at $180{ }^{\circ} \mathrm{C}$ : a tetra-functional epoxy prepolymer mixed with aromatic polyamine curing agents. Sample $B$ uses a more fluid bi-component resin system cured at less than $100{ }^{\circ} \mathrm{C}$ : bisphenol-A and a bi-functional aromatic epoxy resin mixed with aliphatic polyamine and cycloamine curing agents. Product data sheets indicate that both resins exhibit high glass transition temperatures $\left(T_{g}\right)$ after post-cure because of their cross-linked structures. However, sample $A$ epoxy resin system $\left(T_{g} \max =196{ }^{\circ} \mathrm{C}\right)$ shows a stronger thermal stability than sample $B$ resin $\left(T_{g \text { max }}=130{ }^{\circ} \mathrm{C}\right)$ probably thanks to its more restrictive three-dimensional network.

One sample sheet contain on average 30 Vf \% (Vf: volume fraction) of HexTow AS4C high strength carbon fibers (tensile strength $\sigma_{t}=4,385 \mathrm{MPa}, 6,000$ filament count tows, diameter $=6.9 \mu \mathrm{m}$ ). The $0 / 90^{\circ}$ taffetas fabric (Fig. 1), a common woven fabric used among aerospace grade CFRPs, was chosen as the fiber layout. It has to be noted that the AS4C carbon fibers used contain around 1, $3 \%$ of epoxy based sizing materials. The sizing finish aims mainly to facilitate the manipulation of carbon fibers without compromising the adherence between fibers and corresponding polymer matrix. Since the sizing materials are similar to the epoxy resin in chemical composition, they can be removed by appropriate thermal or chemical treatments along with the cross-linked matrix. Clean reclaimed carbon fibers no longer adhere to each other and can thus be considered as unsized. For each composite sheet, the exact mass fraction of unsized carbon fibers was determined and verified by carrying out an acid attack on the composite specimens cut from random places of the original sheet according to the NF EN 2564 [10]: samples are weighed before and after extraction of the resin by sulfuric acid digestion. The values of determined mass fractions were further used in calculating the polymer decomposition rates.

\section{Bench Scale Thermogravimetric Analysis of the Resins}

Prior to semi-industrial tests, thermogravimetric analyses at bench scale were initially performed to investigate the thermal decomposition behavior of the composite samples. A SETARAM TGA 92 mounted with a humidity generator (80 RH \% at $60{ }^{\circ} \mathrm{C}$ ) was used for such purpose. The dynamic temperature program used heats the samples at $5{ }^{\circ} \mathrm{C} \cdot \mathrm{min}^{-1}$ till $800-1,200{ }^{\circ} \mathrm{C}$ under inert (pure nitrogen) or humid (nitrogen + superheated steam) gaseous phase. The main difficulty encountered at this scale is that the specimens have to be cut into $20 \mathrm{mg}$ to be fit in the platinum crucible of the TG analyzer. Resulting specimens as small as $0.2 \mathrm{~cm}^{3}$ cubes present hugely different volume fractions of carbon fibers from one to another. Determination of the final decomposition rate of the polymer matrix after thermal treatments of the composite samples is consequently

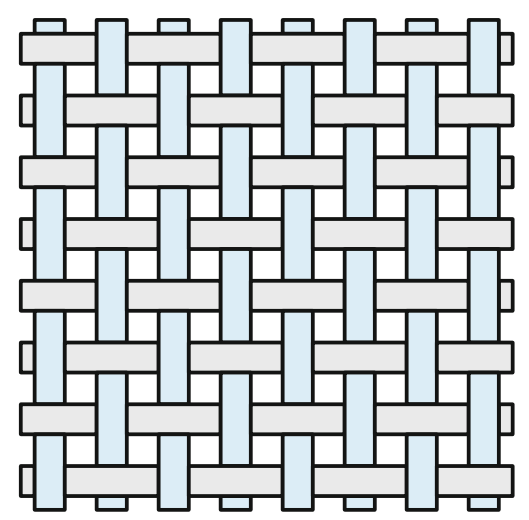

Fig. 1 Taffetas fabric $\left(0 / 90^{\circ}\right)$

impossible. Hereby, TG analysis were carried out only on the cured epoxy resins (noted respectively as resin $A$ and resin $B$ ) solely instead. The gaseous phase composition could not be determined due to the extremely small quantity of sample.

The above thermograms (Fig. 2) shows clearly that both resin $A$ and $B$ start degrading at $250{ }^{\circ} \mathrm{C}$ and the principal weight losses terminate at about $550{ }^{\circ} \mathrm{C}$. This helps to determine the temperature range of the thermal process at semi-industrial scale.

Unlike the quasi-one-stage reaction under pyrolysis, degradation of resin $A$ under steam-thermolysis appears to be a two-stage one (first stage: $-87 \mathrm{wt} \%$, second stage: $-13 \mathrm{wt} \%$ ). Similar results have been found in studies of thermal oxidative decomposition of epoxy resins [11, 12]. Rose et al. suggested that under inert atmosphere, a carbonaceous structure develops and expends at the degradation front (hypothetical two-dimensional surface where the weight loss of solid material takes places) during the thermal degradation of epoxy resin, which eventually decelerates the diffusion-limited decomposition process $[13,14]$. This non permeable coating protects the remaining material from further degradation. M. Blazsó stated that the solid residue of pyrolysis is a rather important part of polymers dominated by aromatic structures, because hydrogen abstraction by the small thermal fragment radicals results in a carbonized network structure of low H/C atomic ratio [15].

As to resin $B$, high decomposition rates (over $90 \%$ ) are achieved in a single stage, probably with limited char formation due to its higher $\mathrm{H} / \mathrm{C}$ atomic ratio compared to resin $A$. The thermogravimetric behaviors of resin $B$ appear similar in both treatments. The final weight loss is yet slightly greater in steam-thermolysis (97 wt $\%)$, where the formed char structure might be better eliminated along with the degradation of resin matrix, than in pyrolysis (93 wt \%).

The superheated steam creates actually a controlled oxidative atmosphere. It is known that under oxidative atmosphere, not only the activation energy of the resin 

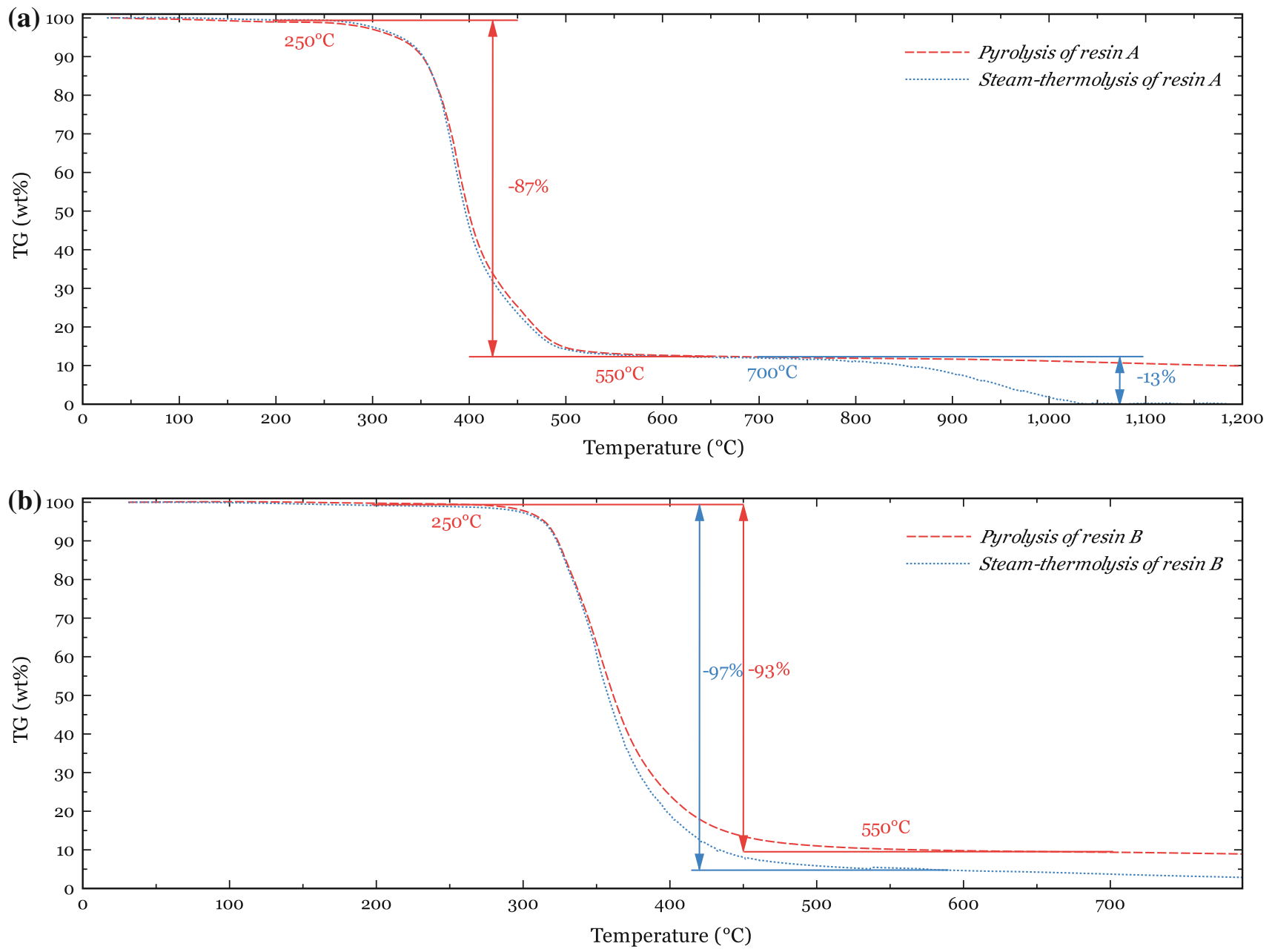

Fig. 2 Thermograms of sample resins under pyrolysis and steam-thermolysis

decomposition is lowered [16], but the elimination of the protective residue can be also accelerated. Although high oxygen level in air increases significantly the decomposition rate of epoxy resin, reclaimed carbon fibers could suffer a steady reduction in tensile strength (approximately $-29 \%$ of the initial value in $60 \mathrm{~min}$ ) [17]. Bai et al. [18] also found that the tensile strength of the recovered carbon fibers decreased rapidly as the decomposition rate increased from 97 to $100 \%$ in their study of the chemical recycling of CFRPs in oxygen in supercritical water. So an excessive oxidation should be avoided when treating CFRPs in order to preserve better mechanical properties of carbon fibers. Moreover, elevated oxygen level (>10\%) in a thermal process presents a potential explosion hazard at industrial scale. While in the steam-thermolysis, superheated steam actually lowers the temperature inside the reactor, and greatly reduces the explosion risk [19]. The emergent question of these bench scale experiments is whether steam-thermolysis achieves complete elimination of the formed char from pyrolysis stage and in the mean time retains most of the tensile strength of reclaimed fibers, as such comes as the main objective of the process optimization. Thus, it has been decided to experiment on real CFRP materials at semi-industrial scale, by operating a specifically designed equipment under selected parameters.

\section{Pilot and Protocol}

Semi-industrial scale experiments were conducted in a sophisticated equipment. It is composed by a vertical cylinder tube furnace, surrounded by heating coils, with an alumina crucible of $1 \mathrm{~L}$ inside. The composite sample sheets were tailored into small plates of $5 \times 5 \times 0.4 \mathrm{~cm}$ before being loaded into the reactor from height. In order to simulate semi-continuous industrial process, the reactor is pre-heated till a target temperature, indicated by a thermocouple inside the crucible. The thermolysis atmosphere is controlled by a steam generator (demineralized water) at 
the entry of the gas inlet providing superheated steam at $180{ }^{\circ} \mathrm{C}$. The flow-rate of the steam is set by a Brooks Instrument mass flow meter. Superheated steam mixed with nitrogen $\left(10 \mathrm{~L} . \mathrm{min}^{-1}\right)$ is then introduced at controlled temperature $\left(200{ }^{\circ} \mathrm{C}\right)$ through six opening holes at the bottom of the crucible throughout the test. Flash introduction of approximately $100 \mathrm{~g}$ of CFRP samples (weighed prior to the treatment) occurs once the parameters stabilize within the target levels (steady state). The counting of the isothermal dwell time starts from this moment. When the heating ends, the introduction of steam is stopped and the system is cooled down under nitrogen to room temperature at a constant rate of $-5{ }^{\circ} \mathrm{C} \cdot \mathrm{min}^{-1}$. A simplified schema of the testing system is presented in Fig. 3:

The remaining carbon fibers are then recovered after being dried in a desiccator and weighed. The final polymer decomposition rate is defined as the final weight loss percentage of the initial polymer matrix:

$r=\frac{\Delta m_{\mathrm{fsolid}}}{m_{\mathrm{icomp}} w_{\mathrm{resin}}}$

with $\Delta m_{\mathrm{f} \text { solid }}=m_{\mathrm{i} \text { comp }}-m_{\mathrm{f} \text { solid }}$ the difference between $m_{\mathrm{i} \text { comp }}$ the initial composite mass and $m_{\mathrm{f} \text { solid }}$ the recovered solid mass after treatment, and $w_{\text {resin }}$ the mass fraction of the resin matrix including sizing materials in the composite samples, determined by chemical degradation previously mentioned.

The tensile strength of the recovered carbon fibers was tested on an INSTRON machine mounted with two vertical load cells of $5 \mathrm{~N}$ pulling at $0.1 \mathrm{~mm} \cdot \mathrm{min}^{-1}$. In accordance with NF ISO 11566, the test specimen contains a $2.5 \mathrm{~cm}-$ long single-filament of recovered fiber, re-examined and verified under optical microscope, glued at its two ends on a paperboard support. The tensile strength test results are based on the mean value of a series of at least twenty specimens of each treatment of CFRP samples. The tensile strength of the virgin sized AS4C carbon fibers were also measured by the same method. The obtained value is different from the value measured by tests on tows, most likely due to the difference in tested gauge lengths, and is thus used as comparable reference. The single-filament testing method is relatively realizable to be put into practice though its reliability awaits further validation according to the ISO standard [21].

Environmental scanning electronic microscopic (ESEM) images of the recovered carbon fibers were also taken as complementary qualitative measures of responses. The ESEM samples were sputter coated with platinum in order to increase their electrical conduction as well as to improve the image resolution.
Fig. 3 Simplified schema of the thermal treatment at semiindustrial scale

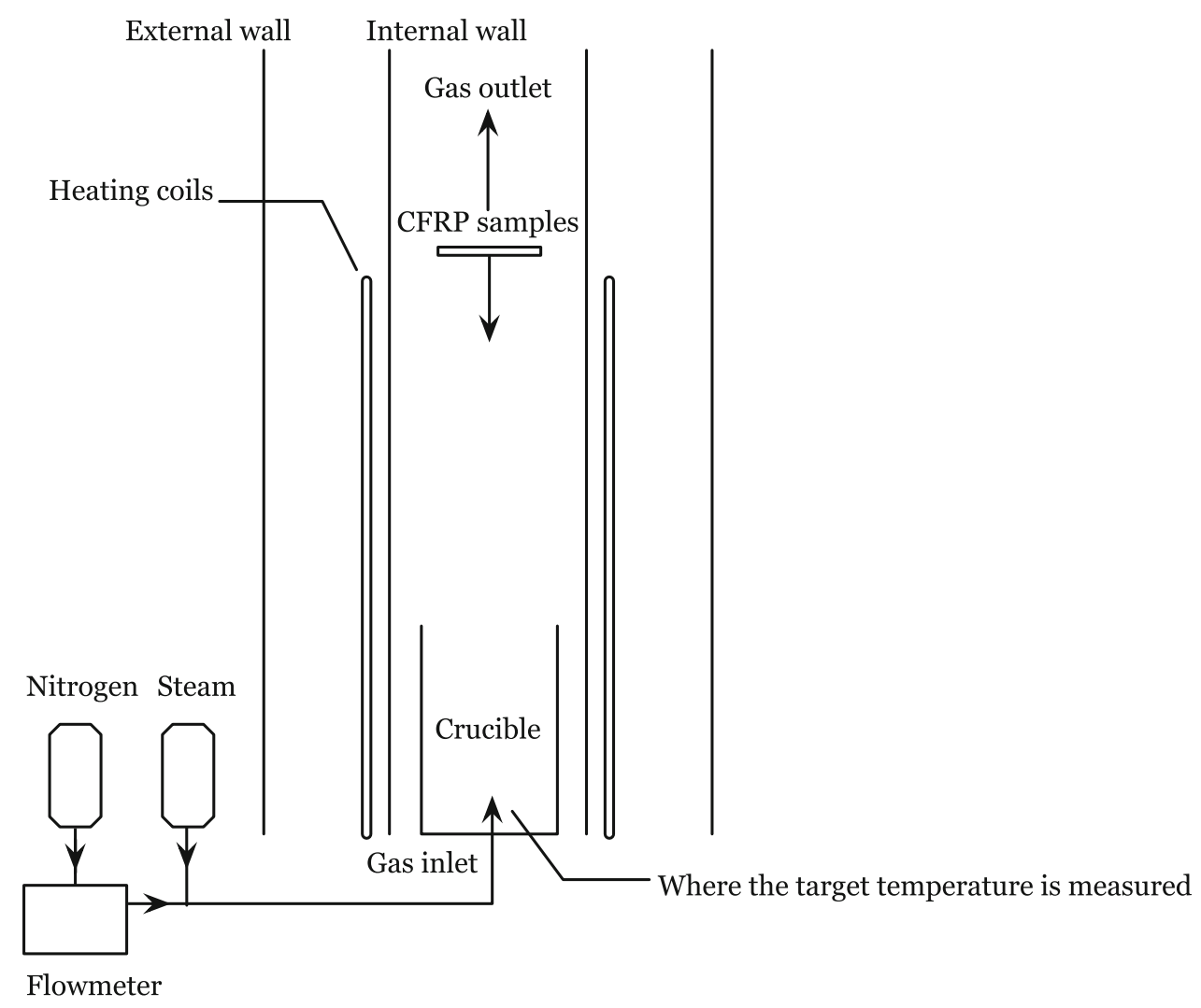




\section{Results and Discussions}

\section{The Taguchi Design Approach}

The Taguchi method brings a considerable improvement to the complete factorial design by simplifying the experimental protocol and reducing the number of tests, allowing highlighting the effect of chosen factors on the response [20]. Genichi Taguchi places the model as a key element of the experimental design strategy. Therefore, the factors to be studied should be adequately chosen by the user according to one's objectives. The Taguchi method defines two types of factors: control factors and noise factors. An inner design constructed over the control factors finds optimum settings. An outer design over the noise factors looks at how the response behaves for a wide rang of noise conditions.

In our study, the experiments are performed on combinations of the inner design runs. Multiple responses are envisaged: ideally complete degradation of polymer matrix and high tensile strength retention are expected to be simultaneously achieved. Complete elimination of the resin and char residue is nevertheless a priority so as to exclude possible contamination in further transformation of the unsized carbon fibers. As to the choice of the factors, three internal factors that could possibly influence either the decomposition rate of polymer matrix either the mechanical properties of recovered fibers are proposed: for each of them two testing levels (low and high) are assessed. The choice of levels is in agreement with the results of TG analysis carried out at bench scale (e.g. the temperature levels are chosen the way to represent the global range observed form TG analysis; the high-level of the isothermal duration is estimated as sufficiently long for a complete matrix degradation; the appropriate steam flow-rate varies from $20 \mathrm{wt} \%$ to in excess $300 \mathrm{wt} \%$ of the initial composite samples).

The primary test table used an $L 4\left(2^{3}\right)$ orthogonal array with only 3 degrees of freedom. Nonetheless, the number of degrees of freedom (DF) can be increased to integrate the background noise by repeating tests under same configurations of factors or by adding additional tests under different configurations. The initial experimental layout is shown in Table 1. The three chosen factors are initially tested without consideration of possible interactions among them. The linear model suggested can be written as following: $\Upsilon=l+\alpha_{1} F_{1}+\alpha_{2} F_{2}+\alpha_{3} F_{3}$, with $\Upsilon$ the response, $l$ the constant of the model, $F_{1-3}$ the factors taken into account, and $\alpha_{1-3}$ the model coefficients.

The linear model is calculated to fit the sequential rows of observations of the test table by the analysis of variance, a mathematical process for separating the variability of a group of observations into assignable causes and setting up various significance tests. It is one of the most generally useful methods of appraising data from designed experiments and is basically a method of comparing several means simultaneously.

\section{Analysis of Variance of Sample A}

Initially the $L 4\left(2^{3}\right)$ orthogonal array test was carried out and the experimental results for CFRP sample $A$ are shown in Table 2. The reproducibility of the results under same experimental configurations was verified by repeating certain tests, which increases the number of degrees of freedom at the same time.

The influences of process parameters on both responses were respectively investigated by analysis of variance technique using standard least squares regression method. The output of the analysis of variance (ANOVA) can be seen in Table 3.

When decomposition rate of epoxy matrix is taken as response, the value of $F$-ratio (the $\mathrm{F}$ test determines whether there are any significant differences among means for a group of regressors), equivalent to the model mean square of 170.5 divided by the error mean square of 3.3 , is 51.7 , implying that the model is statistically significant (the means are not all the same). The probability of exceeding the observed $F$-ratio, assuming no significant differences among the means, indicates that there is only a probability of $3 \times 10^{-4}$ that the model $F$-ratio of 51.7 could occur due to noise. In other words, the parameters differ significantly from one to each other in the way of affecting the decomposition rate of epoxy matrix. However, the influences of the chosen factors on tensile strength of recovered carbon fibers appear insignificant, as the $F$-ratio of 0.94 suggests that the model has to be rejected due to either lack of degrees of freedom or notable noise introduced by the measurement error in the response. The parameter estimates on the decomposition rate of the matrix are listed in Table 4 regardless.

Model coefficient of each factor $F_{1}, F_{2}$ and $F_{3}$ together with the intercept term $l$ are presented. The term Prob $>|t|$ for a single regressor's slope coefficient is the probability of observing that a test statistic is as or more extreme than

Table 1 Experimental application of $L 4\left(2^{3}\right)$ orthogonal array

\begin{tabular}{llll}
\hline Test No. & \multicolumn{4}{l}{ Process parameter level } \\
\cline { 2 - 4 } & $\begin{array}{l}\text { Target } \\
\text { temperature }\left(F_{1}\right)\end{array}$ & $\begin{array}{l}\text { Isothermal } \\
\text { duration }\left(F_{2}\right)\end{array}$ & $\begin{array}{l}\text { Steam flow-rate } \\
\left(F_{3}\right)\end{array}$ \\
\hline 1 & -1 & -1 & -1 \\
2 & -1 & 1 & 1 \\
3 & 1 & -1 & 1 \\
4 & 1 & 1 & -1 \\
\hline
\end{tabular}


Table 2 Experimental results of $L 4\left(2^{3}\right)$ orthogonal array (Sample A)

${ }^{a}$ Including sizing materials

${ }^{\mathrm{b}} \sigma_{\text {virgin }}$

fiber $\cong 3,651 \pm 43 \mathrm{MPa}$,

obtained via single-filament test method \begin{tabular}{llll}
\hline Test No. & Process parameter level (Low $=-1$, & Response 1 & Response 2
\end{tabular} High = 1)

\begin{tabular}{llll}
\hline Target & Isothermal & Steam & Decomposition rate of Tensile strength of
\end{tabular} temperature $F_{1} \quad$ duration $F_{2} \quad$ flow-rate $F_{3} \quad$ epoxy matrix $r(\% \pm 1) \quad$ recovered C fibers ${ }^{\mathrm{b}}$ $\sigma(\mathrm{MPa})$

\begin{tabular}{lrrrrr}
\hline $1_{\mathrm{a}}$ & -1 & -1 & -1 & 79 & $3,464 \pm 35$ \\
$1_{\mathrm{b}}$ & -1 & -1 & -1 & 78 & $3,495 \pm 39$ \\
$2_{\mathrm{a}}$ & -1 & 1 & 1 & 85 & $3,272 \pm 34$ \\
$2_{\mathrm{b}}$ & -1 & 1 & 1 & 84 & $3,285 \pm 37$ \\
$3_{\mathrm{a}}$ & 1 & 1 & -1 & 100 & $3,469 \pm 40$ \\
$3_{\mathrm{b}}$ & 1 & 1 & -1 & 99 & $3,294 \pm 42$ \\
$3_{\mathrm{c}}$ & 1 & 1 & -1 & 95 & $3,097 \pm 31$ \\
$4_{\mathrm{a}}$ & 1 & -1 & 1 & 89 & $3,447 \pm 30$ \\
$4_{\mathrm{b}}$ & 1 & -1 & 1 & 92 & $3,211 \pm 48$ \\
\hline
\end{tabular}

Table 3 ANOVA of $L 4\left(2^{3}\right)$ orthogonal array (Sample $A$ )

\begin{tabular}{|c|c|c|c|c|c|c|c|}
\hline \multirow[t]{2}{*}{ Source } & \multirow[t]{2}{*}{ DF } & \multicolumn{3}{|c|}{ Response 1: decomposition rate of epoxy matrix } & \multicolumn{3}{|c|}{ Response 2: tensile strength of recovered carbon fibers } \\
\hline & & Sum of squares & Mean square & $F$ Ratio & Sum of squares & Mean square & $F$ Ratio \\
\hline Model & 3 & 511.62 & 170.5 & 51.77 & $55,185.22$ & $18,395.1$ & 0.94 \\
\hline Error & 5 & 16.47 & 3.3 & Prob $>F$ & $97,685.67$ & $19,537.1$ & Prob $>F$ \\
\hline C. Total & 8 & 528.09 & & $3 \times 10^{-4 *}$ & $152,870.89$ & & 0.49 \\
\hline
\end{tabular}

* Significant

Table 4 Parameter estimates of $L 4\left(2^{3}\right)$ orthogonal array (Sample A) Response: decomposition rate of epoxy matrix

\begin{tabular}{lrlrl}
\hline Term & Estimates & $\begin{array}{l}\text { Std } \\
\text { error }\end{array}$ & $t$ Ratio & Prob $>|t|$ \\
\hline Intercept $l$ & 87.83 & 0.61 & 142.95 & $<1 \times 10^{-4^{*}}$ \\
Target temperature $F_{1}$ & 6.35 & 0.61 & 10.33 & $1 \times 10^{-4^{*}}$ \\
Isothermal duration & 3.42 & 0.61 & 5.57 & $2.6 \times 10^{-3^{*}}$ \\
$\quad F_{2}$ & & & & \\
Steam flow-rate $F_{3}$ & -0.5 & 0.61 & -0.82 & 0.45
\end{tabular}

* Significant

the one computed from the data assuming that the relevant null hypothesis is true, also called $p$ values. The $p$ values of the target temperature $\left(F_{1}\right)$ and the isothermal duration $\left(F_{2}\right)$ are both very small (respectively $1 \times 10^{-4}$ and $2.6 \times 10^{-3}$ ). This indicates both factors contribute significantly when predicting decomposition rate of the polymer matrix. And the target temperature seems to have the most dominant influence on the polymer matrix degradation efficiency, which (slope term of 6.35) is almost twice as important as the one of the isothermal duration (slope term of 3.42). This is understandable as a complete degradation necessities more energy and possibly longer heating duration. Surprisingly, no significance of the steam flowrate at tested levels (coefficient of -0.5 ) is found, for its $p$ value of 0.45 much greater than the significance level of 0.05 . Such result apparently contradicts the observation in the TG analysis since additional effect of the superheated steam on the degradation of polymer matrix is expected. One possibility is that although the presence of superheated steam has a real impact on the decomposition rate, such effect cannot be observed at the used levels because the steam rates may already be in excess at both high and low levels. Therefore, additional tests, including a steam thermolysis as well as three pyrolysis under different parameter configurations, were added to test this hypothesis. The experimental results of completed tests on sample $A$ is shown in Table 5.

The new low-level of the steam flow-rate actually corresponds to the absence of steam in a pyrolysis process while its high-level remains the same. The previous lowlevel -1 of steam flow-rate is scaled to an intermediate level of 0.08 so as to fit the new model by considering the flowrate as a continuous variable. In addition, a new factor trying to describe the reactive nature of the steam has been proposed and investigated. As previously mentioned, the analyses at thermogravimetric scale showed that the thermal reaction in steam-thermolysis occurs only at high 
Table 5 Experimental results of completed tests (Sample A)

\begin{tabular}{|c|c|c|c|c|c|c|}
\hline \multirow{2}{*}{$\begin{array}{l}\text { Test } \\
\text { No. }\end{array}$} & \multicolumn{4}{|c|}{ Process parameter level $($ Low $=-1$, High $=1)$} & \multirow{2}{*}{$\begin{array}{l}\text { Response } 1 \\
\text { Decomposition rate of epoxy } \\
\text { matrix } r(\% \pm 1)\end{array}$} & \multirow{2}{*}{$\begin{array}{l}\text { Response } 2 \\
\text { Tensile strength of recovered } \mathrm{C} \\
\text { fibers } \sigma(\mathrm{MPa})\end{array}$} \\
\hline & $\begin{array}{l}\text { Target } \\
\text { temperature } F_{l}\end{array}$ & $\begin{array}{l}\text { Isothermal } \\
\text { duration } F_{2}\end{array}$ & $\begin{array}{l}\text { Steam flow- } \\
\text { rate } F_{3}\end{array}$ & $\begin{array}{l}\text { Effect of reactive } \\
\text { steam } F_{4}\end{array}$ & & \\
\hline $1_{\mathrm{a}}$ & -1 & -1 & 0.08 & -1 & 79 & $3,464 \pm 35$ \\
\hline $1_{\mathrm{b}}$ & -1 & -1 & 0.08 & -1 & 78 & $3,495 \pm 39$ \\
\hline $2 \mathrm{a}$ & -1 & 1 & 1 & -1 & 85 & $3,272 \pm 34$ \\
\hline $2 \mathrm{~b}$ & -1 & 1 & 1 & -1 & 84 & $3,285 \pm 37$ \\
\hline $3 \mathrm{a}$ & 1 & 1 & 0.08 & 1 & 100 & $3,469 \pm 40$ \\
\hline $3 \mathrm{~b}$ & 1 & 1 & 0.08 & 1 & 99 & $3,294 \pm 42$ \\
\hline $3 \mathrm{c}$ & 1 & 1 & 0.08 & 1 & 95 & $3,097 \pm 31$ \\
\hline $4 a$ & 1 & -1 & 1 & -1 & 89 & $3,447 \pm 30$ \\
\hline $4_{b}$ & 1 & -1 & 1 & -1 & 92 & $3,211 \pm 48$ \\
\hline 5 & 1 & -1 & 0.08 & -1 & 91 & $2,972 \pm 43$ \\
\hline 6 & -1 & -1 & -1 & -1 & 80 & $3,481 \pm 53$ \\
\hline 7 & -1 & 1 & -1 & -1 & 78 & $3,462 \pm 54$ \\
\hline 8 & 1 & 1 & -1 & -1 & 83 & $3,581 \pm 38$ \\
\hline
\end{tabular}

Table 6 ANOVA of completed tests (Sample $A$ )

\begin{tabular}{|c|c|c|c|c|c|c|c|}
\hline \multirow[t]{2}{*}{ Source } & \multirow[t]{2}{*}{ DF } & \multicolumn{3}{|c|}{ Response 1: decomposition rate of epoxy matrix } & \multicolumn{3}{|c|}{ Response 2: tensile strength of recovered carbon fibers } \\
\hline & & Sum of squares & Mean square & $F$ Ratio & Sum of squares & Mean square & $F$ Ratio \\
\hline Model & 3 & 678.21 & 169.6 & 26.7 & $101,449.37$ & $25,362.3$ & 0.73 \\
\hline Error & 9 & 50.8 & 6.4 & Prob $>F$ & $278,835.86$ & $34,854.5$ & Prob $>F$ \\
\hline C. Total & 12 & 729.0 & & $1 \times 10^{-4 *}$ & $380,285.23$ & & 0.6 \\
\hline
\end{tabular}

\footnotetext{
* Significant
}

temperature during the later phase of the degradation of cured epoxy system. It is judicious to take into account the resulting effect of the combination of the three individual parameters, as a categorical variable rather than a continuous one. The high-level of such factor corresponds to the configuration where steam is superheated until the highest target temperature during the longest heating duration while its low-level represents the remaining scenarios.

The ANOVA after rerunning the model (Table 6) shows that the model predicting the decomposition rate of epoxy matrix fits more tightly with the experimental results (model $p$ value is $1 \times 10^{-4}$ ). The resulting model parameter estimates are listed in Table 7. But the significance of the model predicting the tensile strength of recovered carbon fibers remains low $(p$ value $=0.60)$. The low significance of the model doesn't necessarily mean that there is no effect of the studied factors on the response. On the contrary, it could be suspected that all factors have equally important impacts on the responses, that is, they all contribute to the reduction of the tensile strength of the recovered fibers in one way or another.

It is found that the three major factors affecting the decomposition rate of epoxy matrix are, in order of increasing influence, the steam flow-rate (slope term of 2.93), the target temperature (slope term of 3.63) and the effect of the steam at high temperature during the phase of char elimination (slope term of 5.01). The constant term of 89.24 implies an average final decomposition rate around $89 \%$ whatever configuration of the process parameters. This value is in close agreement with the decomposition rate after the one-stage pyrolysis observed at thermogravimetric scale. The very low $p$ values of the target temperature $\left(2.6 \times 10^{-3}\right)$ and the steam effect $\left(2.4 \times 10^{-3}\right)$ indicate that both model coefficients are significant. While the effect of the steam flow-rate solely appears statistically less significant $(p$ value $=0.02$ ), the isothermal duration has almost no contributions to the prediction of polymer matrix decomposition rate. From a 
Table 7 Parameter estimates of completed tests (Sample A)

\begin{tabular}{lrrrl}
\hline Response: Decomposition rate of epoxy matrix \\
\hline Term & Estimates & $\begin{array}{l}\text { Std } \\
\text { error }\end{array}$ & $t$ Ratio & Prob $>|t|$ \\
\hline Intercept $l$ & 89.24 & 0.99 & 90.22 & $<1 \times 10^{-4^{*}}$ \\
Target temperature $F_{1}$ & 3.63 & 0.85 & 4.29 & $2.6 \times 10^{-3}$ \\
Isothermal duration $F_{2}$ & -0.01 & 0.84 & -0.01 & 0.99 \\
Steam flow-rate $F_{3}$ & 2.93 & 0.98 & 3.01 & $0.02^{*}$ \\
Effect of steam $F_{4}$ & 5.01 & 1.15 & 4.35 & $2.4 \times 10^{-3} *$ \\
\hline
\end{tabular}

* Significant

Table 8 Improved ANOVA and parameter estimates (Sample A)

\begin{tabular}{|c|c|c|c|c|c|c|}
\hline \multicolumn{7}{|c|}{ Response: decomposition rate of epoxy matrix } \\
\hline \multirow{2}{*}{$\frac{\text { Source }}{\text { Model }}$} & \multirow{2}{*}{$\frac{\mathrm{DF}}{3}$} & \multicolumn{2}{|c|}{ Sum of squares } & \multicolumn{2}{|c|}{ Mean square } & \multirow[t]{2}{*}{$F$ Ratio } \\
\hline & & 678 & 21 & 226.07 & & \\
\hline Error & 9 & 50 & & 5.65 & & Prob $>F$ \\
\hline C. Total & 12 & 729 & 01 & & & $<1 \times 10^{-4 *}$ \\
\hline \multicolumn{3}{|l|}{ Term } & Estimates & Std error & $t$ Ratio & Prob $>|t|$ \\
\hline \multicolumn{3}{|c|}{ Intercept $l$} & 89.23 & 0.84 & 106.05 & $<1 \times 10^{-4^{*}}$ \\
\hline \multicolumn{3}{|c|}{ Target temperature $F_{1}$} & 3.63 & 0.77 & 4.69 & $1.1 \times 10^{-3 *}$ \\
\hline \multicolumn{3}{|c|}{ Steam flow-rate $F_{2}$} & 2.94 & 0.92 & 3.2 & $0.01^{*}$ \\
\hline \multicolumn{3}{|c|}{ Effect of steam $F_{3}$} & 5.01 & 0.91 & 5.49 & $4 \times 10^{-4 *}$ \\
\hline
\end{tabular}

* Significant

chemical point of view, this can be explained by the hypothesis that after protective char layer being formed at the front of resin degradation, further heating under inert atmosphere would be unable to complete carbonaceous residues degradation.

By rejecting the isothermal dwell time parameter, the ANOVA of the improved model is obtained with the parameter estimates of the three determined major factors as shown in Table 8.

The significance of the effect of superheated steam and that of the target temperature are proved by the tight fit of the model $\left(p\right.$ value $<1 \times 10^{-4}$ ). The hypothesis of excessive steam flow-rate level in the previous $L 4\left(2^{3}\right)$ orthogonal array model is thus verified. The leverage plot [22] of the improved model is shown in Fig. 4. The distance from a point to the line of fit (red solid line) shows the actual residual. The distance from the point to the horizontal line of the mean (blue dashed line) shows what the residual error would be without the effect in the model. In other words, the mean line in the leverage plot represents the model where the hypothesized value of the parameter (effect) is constrained to zero. As the actual experimental values are matched by the predicted ones, most of the points on the scatterplot fall close around the line of fit

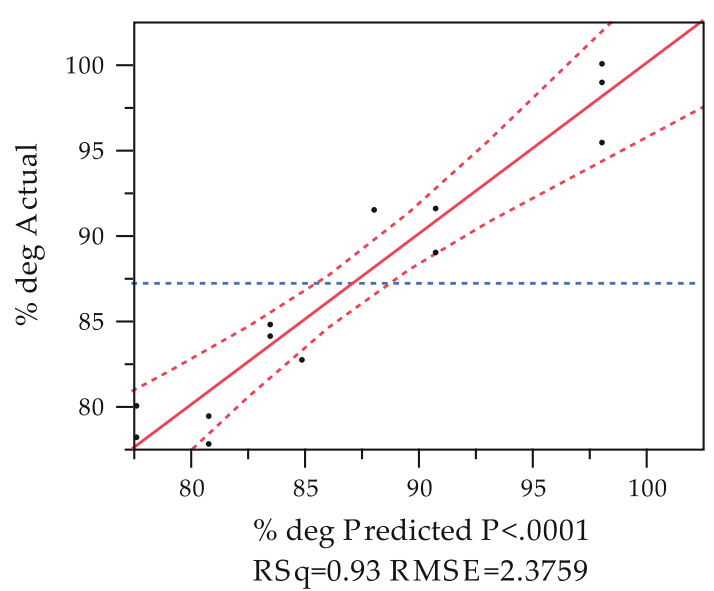

Fig. 4 Actual by predicted plot of improved model on resin decomposition rate (sample $A$ )

inside the $95 \%$ confidence curve (red dashed lines), which indicates a good prediction. The r-squared value (coefficient of determination), which is the square of the sample correlation coefficient between the outcomes and the values of the singer regressor being used for prediction, suggests that $93 \%$ of variability in decomposition rate of epoxy matrix can be explained by the model. In fact, the matrix decomposition rate of $89 \%$ resulted from pyrolytic phase is hardly dependent of the chosen parameter levels, while additional decomposition is realizable only under steam-thermolysis at elevated temperature. According to the model prediction, a quasi-complete final decomposition rate of the epoxy $A$ matrix $(>98 \%$ ) could be obtained using a mild steam flow-rate: $r=l+\alpha_{1} F_{1}+\alpha_{2} F_{2}+\alpha_{3}$ $F_{3}=(89.23+3.63 \times 1+\times 2.94 \times 0.08$ $+5.01 \times 1) \% \cong 98.1 \%$ (test no 3 ).

Furthermore, the reclaimed carbon fibers from the optimal steam-thermal test (in term of resin decomposition rate) and those from conventional pyrolysis were examined under environmental scanning electronic microscope along with the virgin sized and chemically unsized ones (Figs. 5, 6, 7 and 8).

As can be seen from the ESEM images, the virgin sized carbon fibers adhere to each other thanks to the sizing materials. The striations on the unsized virgin carbon fibers along the longitude can be more clearly identified on the surface. The carbon fibers reclaimed from the optimal steam-thermal treatment possess a rather clean surface, similar to the virgin unsized ones, though tiny defaults and small quantity of residual matrix material can be occasionally found on the surface of recovered fibers suggesting slight fiber damage. No reduction in diameters of the reclaimed fibers is observed. The pyrolysis using the same target temperature and the same heating duration resulted, however, an incomplete matrix degradation. Most of recovered carbon fibers are covered by a layer of 

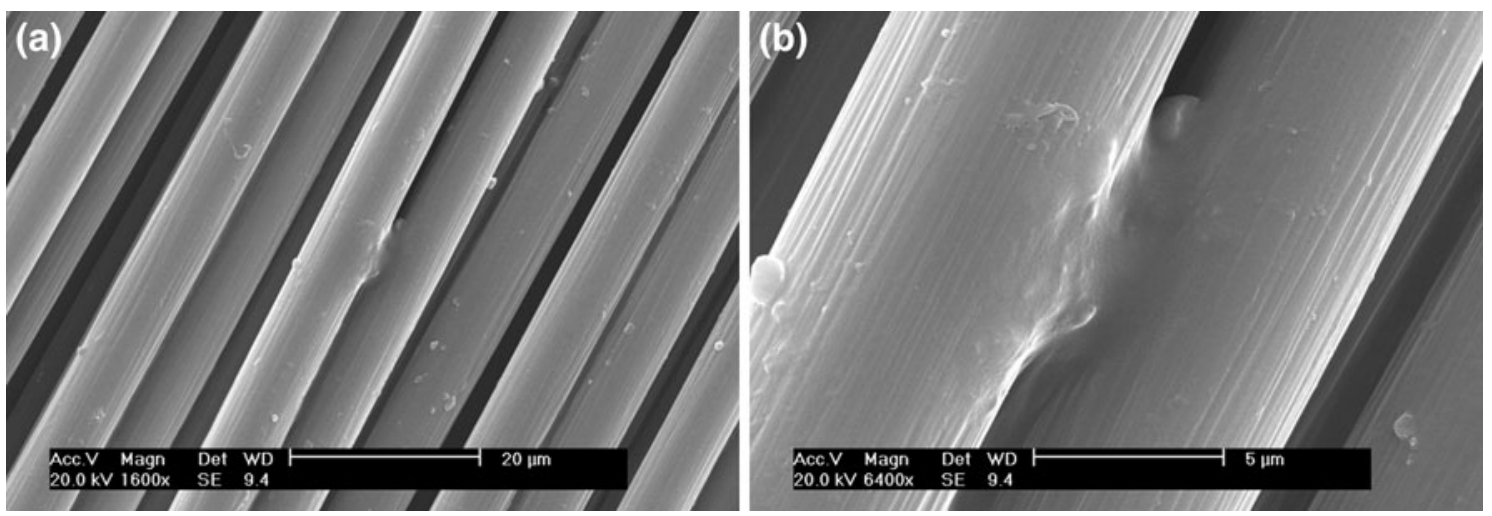

Fig. 5 Virgin sized AS4C CF (magnification: left $\times 1,600$, right $\times 6,400$ )
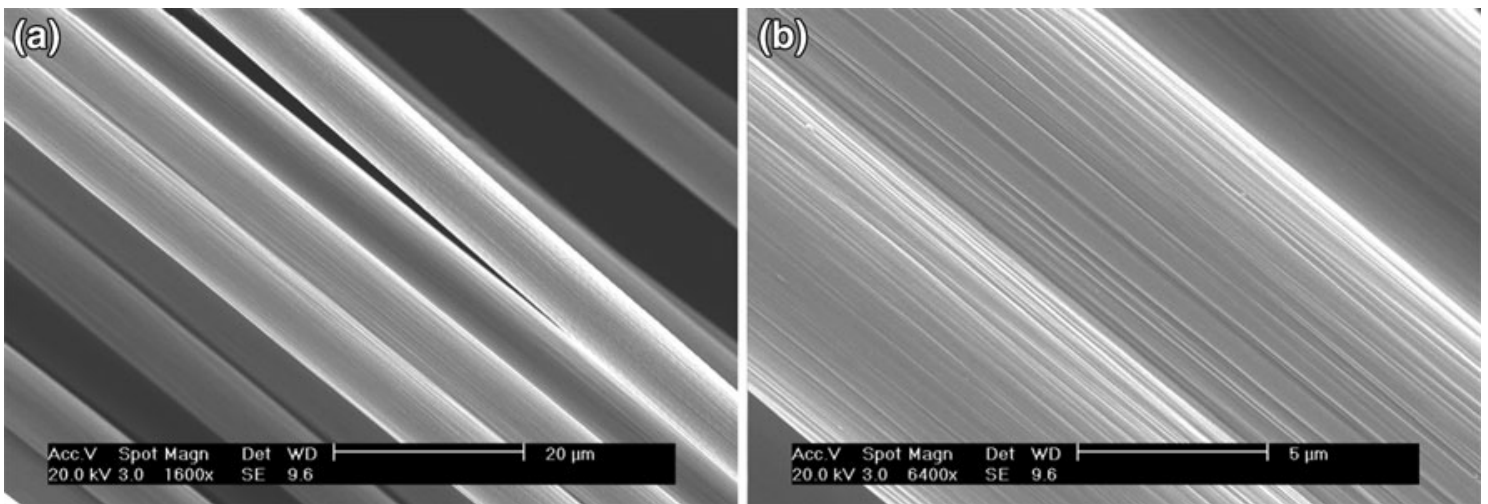

Fig. 6 Virgin unsized AS4C CF (magnification: left $\times 1,600$, right $\times 6,400$ )

carbonaceous residues. All of the ESEM observations confirmed the ANOVA results. The superheated steam at high temperature is proved efficient in eliminating the char formed from thermal degradation of the resin matrix in the case of sample $A$.

\section{Analysis of Variance of Sample B}

Same ANOVA approach was applied to semi-industrial test results on sample $B$ (Table 9).

In the same way as sample $A$ tests, experiments have been repeated and completed to verify and to validate the design. The results of the repeated tests show an admissible reproducibility of the test responses. The steam flow-rate level has been rescaled to $[-1,1]$ interval with the -1 low-level standing for the inert atmosphere in pyrolysis (where the steam flow-rate is null). A lower steam flow-rate level $(-0.45)$ was also integrated. The first ANOVA results are presented in Table 10.

The model predicting the decomposition rate of epoxy matrix fits relatively well with the actual values ( $p$ value $=7.7 \times 10^{-3}$, model significant $)$. Still the model predicting the tensile strength of recovered carbon fibers remains insignificant ( $p$ value $=0.12$ ). The influence of all four proposed factors (three original plus a hypothetic one) on the decomposition rate of epoxy matrix are classified in Table 11.

The parameter estimates shows a slightly different picture from the one obtained from ANOVA of experimental results on sample $A$. The intercept term of $94 \%$ indicates that a higher decomposition rate of epoxy matrix can be achieved for sample $B$ than sample $A$. Moreover, the target temperature is insignificant within the levels given, which also implies the possibility of a lower degradation temperature of the carbonaceous residues. The isothermal dwell time, as in the case of sample $A$, seems to manifest no effect on the matrix decomposition rate while the steam flow-rate and the combined effect of three individual parameters have both non negligible impacts on the decomposition rate. After ignoring the insignificant parameters, a better model fit is given by the improved ANOVA (Table 12 and Fig. 9).

The $p$ values of the model and the parameters indicate a reliable prediction of the decomposition rate of epoxy matrix of sample $B$. The influence of the steam flow-rate and that of the combined effect are almost equally important on the response because the target temperature 

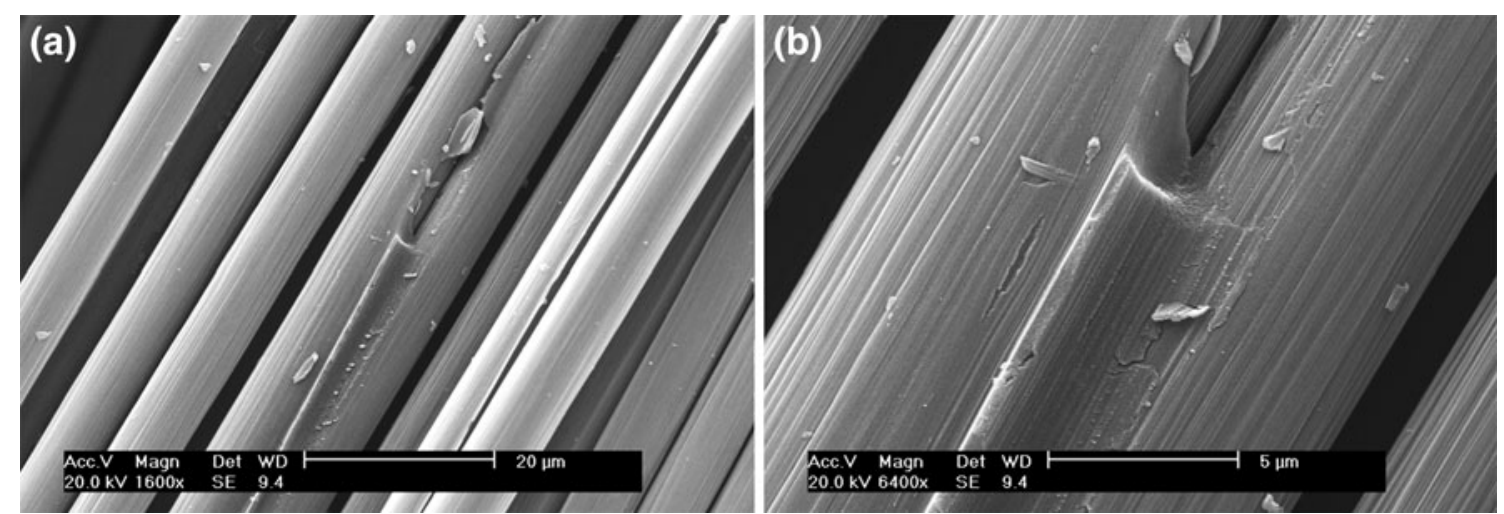

Fig. 7 Recovered CF from the optimal steam-thermal treatment (magnification: left $\times 1,600$, right $\times 6,400$ )
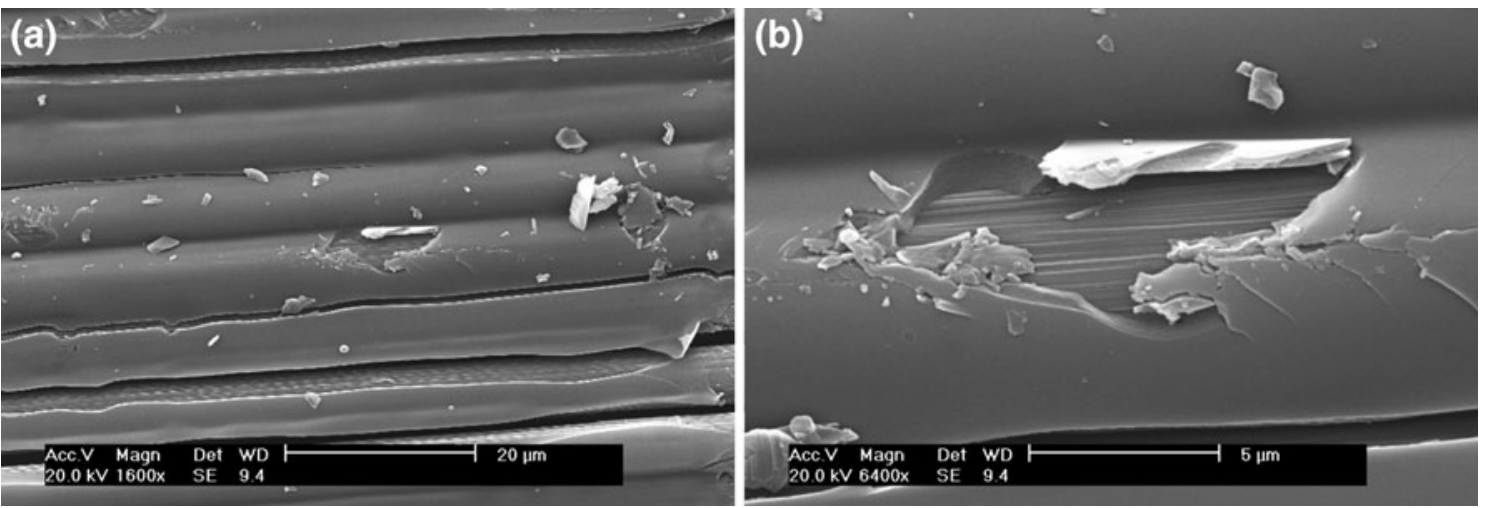

Fig. 8 Recovered CF from pyrolysis under same temperature and heating duration (magnification: left $\times 1,600$, right $\times 6,400$ )

Table 9 Experimental results of completed tests (Sample $B$ )

\begin{tabular}{|c|c|c|c|c|c|c|}
\hline \multirow{2}{*}{$\begin{array}{l}\text { Test } \\
\text { No. }\end{array}$} & \multicolumn{4}{|c|}{ Process parameter level $($ Low $=-1$, High $=1)$} & \multirow{2}{*}{$\begin{array}{l}\text { Response } 1 \\
\text { Decomposition rate of epoxy } \\
\text { matrix } r(\% \pm 1)\end{array}$} & \multirow{2}{*}{$\begin{array}{l}\text { Response } 2 \\
\text { Tensile strength of recovered } \\
\text { C fibers } \sigma(\mathrm{MPa})\end{array}$} \\
\hline & $\begin{array}{l}\text { Target } \\
\text { temperature } F_{1}\end{array}$ & $\begin{array}{l}\text { Isothermal } \\
\text { duration } F_{2}\end{array}$ & $\begin{array}{l}\text { Steam flow- } \\
\text { rate } F_{3}\end{array}$ & $\begin{array}{l}\text { Effect of reactive } \\
\text { steam } F_{4}\end{array}$ & & \\
\hline 1 & -1 & -1 & 0.08 & -1 & 91 & $3,566 \pm 50$ \\
\hline $2 a_{a}$ & -1 & 1 & 1 & -1 & 97 & $3,652 \pm 49$ \\
\hline $2 \mathrm{~b}$ & -1 & 1 & 1 & -1 & 96 & $3,458 \pm 43$ \\
\hline $2_{c}$ & -1 & 1 & 1 & -1 & 92 & $3,531 \pm 44$ \\
\hline $2 \mathrm{~d}$ & -1 & 1 & 1 & -1 & 92 & $3,654 \pm 50$ \\
\hline 3 & 1 & 1 & 0.08 & 1 & 99 & $3,612 \pm 48$ \\
\hline 4 & 1 & -1 & 1 & -1 & 95 & $3,377 \pm 49$ \\
\hline 5 & 1 & 1 & -1 & -1 & 81 & $3,196 \pm 36$ \\
\hline 6 & 1 & 1 & -0.45 & 1 & 99 & $3,659 \pm 34$ \\
\hline 7 & 1 & -1 & -0.45 & -1 & 89 & $3,478 \pm 27$ \\
\hline 8 & -1 & -1 & -1 & -1 & 77 & $3,262 \pm 32$ \\
\hline
\end{tabular}

even at its low-level is sufficiently elevated to degrade most of the resin $B$. The r-squared value of the actual versus predicted plot of $85 \%$, is not as high as the one in the case of the model for sample $A$, but still an acceptable one.
ESEM images are also taken on the carbon fibers recovered from the non-optimal steam-thermal treatment and the optimal one. Although in both cases the final decomposition rate of epoxy matrix reaches over $94 \%$ (non-optimal treatment: $95 \%$, optimal treatment: $99 \%$ ), 
Table 10 ANOVA of completed tests (Sample $B$ )

\begin{tabular}{|c|c|c|c|c|c|c|c|}
\hline \multirow[t]{2}{*}{ Source } & \multirow[t]{2}{*}{ DF } & \multicolumn{3}{|c|}{ Response 1: decomposition rate of epoxy matrix } & \multicolumn{3}{|c|}{ Response 2: tensile strength of recovered carbon fibers } \\
\hline & & Sum of squares & Mean square & $F$ Ratio & Sum of squares & Mean square & $F$ Ratio \\
\hline Model & 4 & 417.28 & 104.3 & 10.15 & $168,088.75$ & $42,022.2$ & 2.86 \\
\hline Error & 6 & 61.68 & 10.3 & Prob $>F$ & $88,035.25$ & $14,672.5$ & Prob $>F$ \\
\hline C. Total & 10 & 478.95 & & $7.7 \times 10^{-3 *}$ & $256,124.00$ & & 0.12 \\
\hline
\end{tabular}

* Significant

Table 11 Parameter estimates of completed tests (Sample B)

\begin{tabular}{|c|c|c|c|c|}
\hline \multicolumn{5}{|c|}{ Response: decomposition rate of epoxy matrix } \\
\hline Term & Estimates & $\begin{array}{l}\text { Std } \\
\text { error }\end{array}$ & $t$ Ratio & Prob $>|t|$ \\
\hline Intercept $l$ & 94.05 & 1.51 & 62.22 & $<1 \times 10^{-4 *}$ \\
\hline Target temperature $F_{1}$ & 0.99 & 1.24 & 0.8 & 0.46 \\
\hline Isothermal duration $F_{2}$ & -0.46 & 1.2 & -0.39 & 0.71 \\
\hline Steam flow-rate $F_{3}$ & 7.07 & 1.42 & 4.98 & $2.5 \times 10^{-3}$ \\
\hline Effect of steam $F_{4}$ & 5.75 & 1.67 & 3.44 & $0.01^{*}$ \\
\hline
\end{tabular}

* Significant

Table 12 Improved ANOVA and parameter estimates (Sample B)

\begin{tabular}{lccccl}
\hline Response: & decomposition rate of epoxy matrix \\
\hline Source & DF & Sum of squares & Mean square & $F$ Ratio \\
\hline Model & 2 & 407.59 & 203.8 & 22.85 \\
Error & 8 & 71.36 & 2.92 & Prob $>F$ \\
C. Total & 10 & 478.95 & & & $5 \times 10^{-4}$ \\
\hline Term & Estimates & SE & $t$ Ratio & Prob $>|t|$ \\
\hline Intercept $l$ & 94.16 & 1.17 & 80.54 & $<1 \times 10^{-4^{*}}$ \\
Steam flow-rate $F_{1}$ & 6.46 & 1.16 & 5.55 & $5 \times 10^{-4}$ \\
Effect of steam $F_{2}$ & 6.05 & 1.2 & 5.04 & $1 \times 10^{-3}$ \\
\hline
\end{tabular}

* Significant

there is a difference between the states of the recovered carbon fibers (Figs. 9, 10).

Certain carbon fibers recovered from the non-optimal treatment are still attached by a layer of char, while the optimal steam-thermal treatment yields clean carbon fibers with few carbonaceous residues on the surface and no obvious reduction in fiber diameter is found. This means that, to reclaim virgin-like carbon fibers, the decomposition rate of polymer matrix must be at least greater than $95 \%$. By using a modest quantity of steam in the thermal treatment, clean separated carbon fibers can be obtained. The average tensile strength obtained of those recovered from optimal steam-thermal conditions (Test No. 3 and 6) are

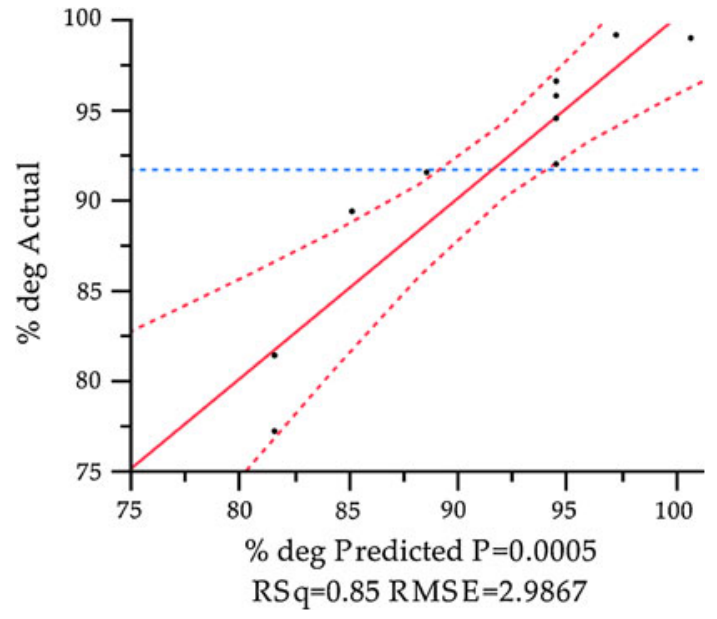

Fig. 9 Actual by predicted plot of improved model on resin decomposition rate (sample $B$ )

around 3,636 MPa, which is almost $100 \%$ of the value of virgin AS4C fibers (Fig. 11).

\section{Conclusion and Perspectives}

In this paper, the effects of process parameters on two key responses encountered in the steam-thermal recycling of the CFRP materials have been investigated. For the purpose of reclaiming clean carbon fibers without severe reduction in tensile strength, experimental designs using Taguchi method were realized successively on two epoxy based CFRP samples. Sample $A$ contains a most thermally stable aromatic resin system while sample $B$, embeds BPA resin and non-aromatic amine curing agents. The resin matrices of both samples degrade within the same temperature range but sample $B$ yields fewer char residues than sample $A$ (sample $B$ has a higher $\mathrm{H} / \mathrm{C}$ atomic ratio of its resin matrix). The effects of three factors (target heating temperature, steam flow-rate and heating duration) were initially investigated. The ANOVA and standard least squares linear regression of the experimental results shows that, for sample $A$ : the decomposition rate of epoxy resin is directly related with the steam flow-rate (or rather the mass 

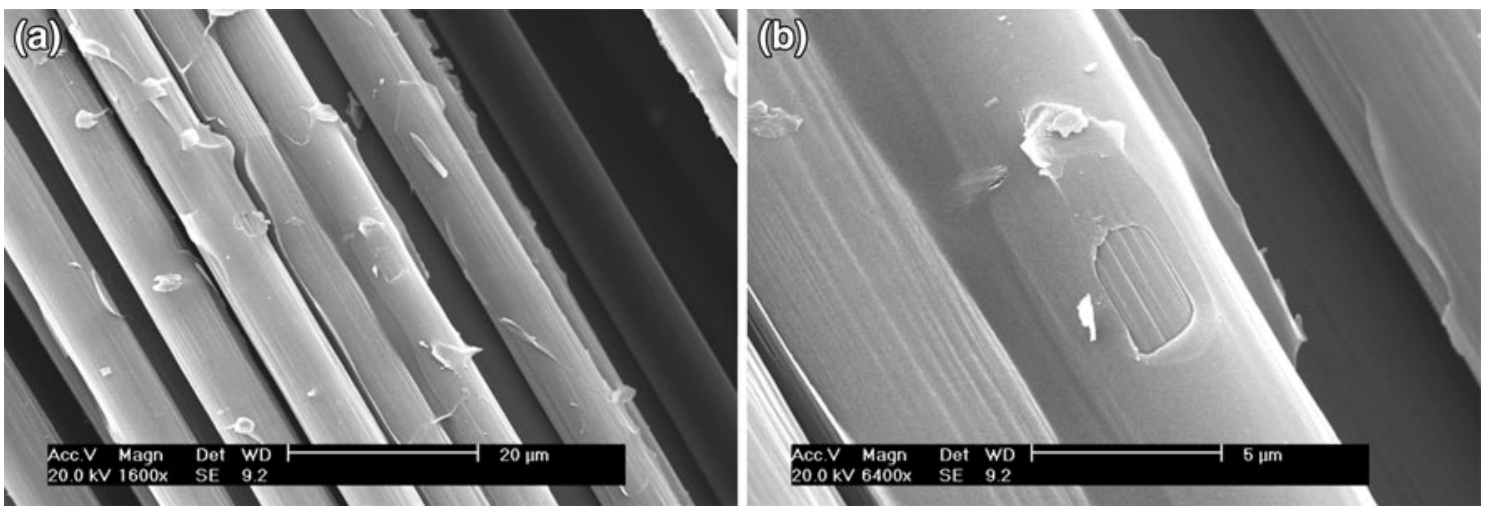

Fig. 10 Recovered CF from the non-optimal steam-thermal treatment (magnification: left $\times 1,600$, right $\times 6,400$ )
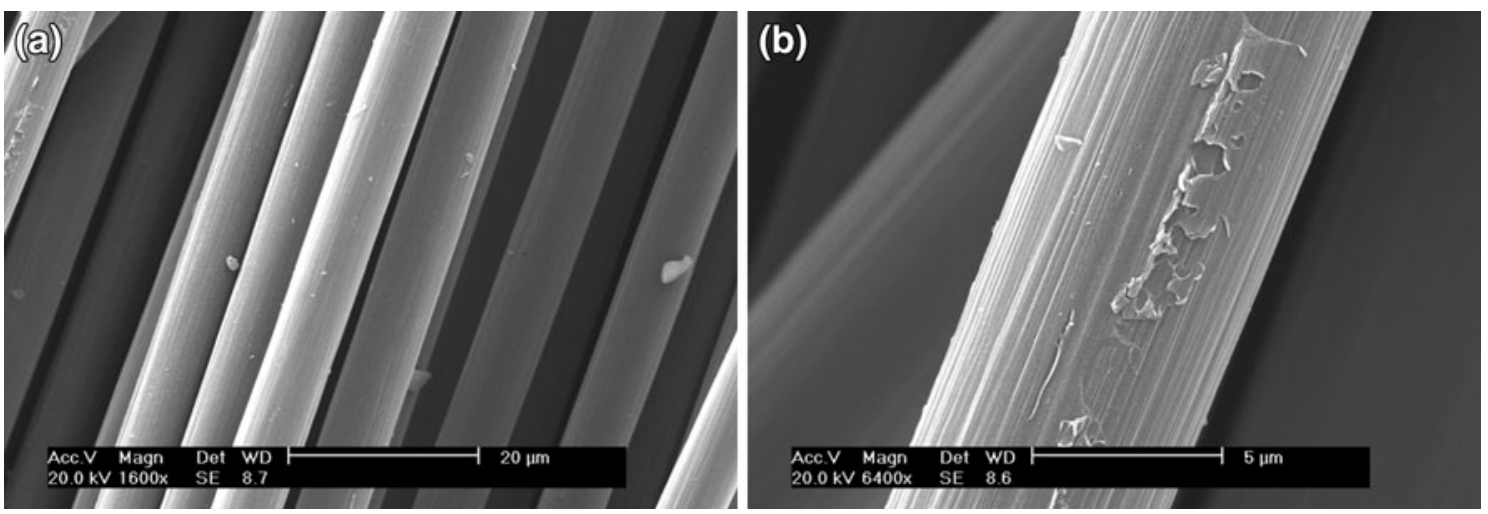

Fig. 11 Recovered CF from the optimal steam-thermal treatment (magnification: left $\times 1,600$, right $\times 6,400$ )

ratio steam/sample), the heating temperature, and the presence of steam at higher temperature during the later stage of the thermal treatment, in order of increasing influence; for sample $B$ : the resin decomposition rate reaches easily to $94 \%$ as lower quantity of carbonaceous structure are formed from pyrolysis stage of resin network. Yet, to degrade quasi-completely the remaining char residues on the surface of carbon fibers, superheated steam at relatively high temperature is needed, so as to overcome the activation energy of decomposition reactions. This point of view is supported by both bench and semi-industrial scale tests as well as ESEM scrutinization.

The influences of the process parameters on the tensile strength of the recovered carbon fibers, however, cannot be determined within attributed levels, seeing that the linear model is insignificant. As a matter of fact, large errors can be introduced during the manipulation of the single-filaments, as separated unsized carbon fibers are extremely difficult to handle, fragile and easily broken. Besides, large standard deviations of values measured by the single-filament strength test were found, which were directly related to the insignificance of the model prediction. It is highly possible that all studied process parameters contribute to a limited tensile strength loss during the treatments. Therefore, it is desirable to lower the target heating temperature, to reduce the dwell time and possibly the steam flow-rate, providing that a complete decomposition rate of matrix was achieved.

Inevitably, a compromise should be made between reaching a complete degradation of the polymer matrix and preventing the tensile strength loss of the recovered fibers, to be consistent with the constraints of future fiber reuse processes. Due to the incompatibility issue of the treated fibers, the complete decomposition of epoxy matrix is decided to be the priority. Despite the insignificance of the model on tensile strength prediction, reclaimed resin (or residue) free carbon fibers retain more or less over $90 \%$ of its original tensile strength. This confirms the feasibility of reclaiming high quality residue free carbon fibers by optimized steam-thermolysis.

Further studies are required to fully understand the role of the superheated steam in steam-thermolysis and to establish carbon balance sheets, mainly through additional confirmation tests with physicochemical characterizations of emitted gas-phase. The recycled carbon fiber/matrix compatibility issue will also be tackled by analyzing the 
chemical state of reclaimed fiber surfaces with or without further surface treatment and by mechanical tests of the composites made of reused carbon fibers.

Acknowledgments The authors would like to express their deep gratitude towards French Agency for Environment and Energy Management (ADEME) for sponsoring the research work.

\section{References}

1. Mondal, S.: Frost \& Sullivan: Supply Chain Analysis of the Automotive Carbon Fiber Composites Market. (December 2011)

2. JCMA (The Japan Carbon Fiber Manufacturers Association) Automobile and Airplane LCA (2008)

3. Directive 2000/53/EC of the European parliament and of the council of 18 September 2000 on end-of-life vehicles

4. McConnell, V.P.: Launching the carbon fiber recycling industry. Reinf. Plast. 54(2), 33-37 (2010)

5. Lester, E., et al.: Microwave heating as a means for carbon fiber recovery from polymer composites: a technical feasibility study. Mater. Res. Bull. 39(10), 1549-1556 (2004)

6. Cunliffe, A.M., et al.: Recycling of fiber-reinforced polymeric waste by pyrolysis: thermo-gravimetric and bench-scale investigations. J. Anal. Appl. Pyrol. 70(2), 315-338 (2003)

7. Piñero-Hernanz, R., et al.: Chemical recycling of carbon fiber composites using alcohols under subcritical and supercritical conditions. J. Supercrit. Fluids 46(1), 83-92 (2008)

8. Goto, M.: Chemical recycling of plastics using sub-and supercritical fluids. J. Supercrit. Fluids 47(3), 500-507 (2009)

9. Piñero-Hernanz, R., et al.: Chemical recycling of carbon fiber reinforced composites in nearcritical and supercritical water. Compos. A 39(3), 454-461 (2008)

10. EN 2564: Carbon fiber laminates. Determination of the fiber, resin and void contents (September 1998)
11. Jiang, G., et al.: Soft ionisation analysis of evolved gas for oxidative decomposition of an epoxy resin/carbon fiber composite. Thermochim. Acta 454(2), 109-115 (2007)

12. Wang, Q., et al.: Kinetics study of thermal decomposition of epoxy resins containing flame retardant components. Polym. Degrad. Stab. 91(8), 1747-1754 (2006)

13. Rose, N., et al.: Thermal oxidative degradation of epoxy resins: evaluation of their heat resistance using invariant kinetic parameters. Polym. Degrad. Stab. 45(3), 387-397 (1994)

14. Le Bras, M., et al.: The degradation front model-a tool for the chemical study of the degradation of epoxy resins in fire. J. Fire Sci. 14(3), 199-234 (1996)

15. Blazsó, M.: Pyrolysis for recycling waste composites. Management, Recycling and Reuse of Waste Composites (December 2009) pp. 102-114

16. Chen, K.S., et al.: Kinetics of thermal decomposition of epoxy resin in nitrogen-oxygen atmosphere. J. Environ. Eng. 123(10), 1041-1046 (1997)

17. Pickering, S.: Thermal methods for recycling waste composites. Management, Recycling and Reuse of Waste Composites (December 2009) pp. 74-82

18. Bai, Y., et al.: Chemical recycling of carbon fibers reinforced epoxy resin composites in oxygen in supercritical water. Mater. Des. 31(2), 999-1002 (2010)

19. Kalitko, V.A.: Steam-thermal recycling of tire shreds: calculation of the rate of explosion-proof feed of steam. J. Eng. Phys. Thermophys. 81(4), 781-786 (2008)

20. Sabre, R.: Plans d'expériences: Méthode de Taguchi. Techniques de l'ingénieur Agroalimentaire (mars 2007)

21. ISO 11566: Carbon fiber-Determination of the tensile properties of single-filament specimens (November 1997)

22. Sall, J.: Leverage plots for general linear hypotheses. Am. Stat. (1990) 44(4), 308-315 (18 ref.) 